\title{
Re-conceptualizing Holistic Assessment of Culture-Based Learning of English as a Foreign Language in Higher Education for the 21st-Century Classroom
}

\author{
Aryusmar and Wiwiek Afifah
}

\begin{abstract}
Along with the need for assessment of English as a foreign language learning with cultural focus, some theories in this field should be re-examined and adapted. Additionally, the 21st- century classroom is also more dynamic thus the assessment that will be used by the English lecturer must be well comprehensive. To do this, the new classroom condition of the 21st-century is used as the basic consideration of learners' needs. Therefore, the re-conceptualizing holistic assessment for culture-based English as a foreign language learning should be based on the integration of the modern assessment such as self-assessment, peer-assessment, authentic assessment, classroom assessment, and the objective assessment either formative and summative assessment. Finally, the implementation of holistic assessment can be done using online assessment or web-based assessment in which lecturer can directly upgrade the existing assessment to be blended model of assessment.
\end{abstract}

Index Terms - Culture-based, English as a foreign language leaning, holistic assessment.

\section{INTRODUCTION}

The growing interest in assessment for language learning is rapidly expanding. Among them are Tosuncuoglu [1] who explains about the importance of assessment in ELT, Green [2] who explains about assessment for Learning in Language Education, Bisai \& Singh [3] who criticized the assessment which is practiced in a very much monolingual in multilingual classroom, and Cowie \& Sakui [4] who investigate the current trend in evaluation. The amount of research describing the success of culture-based English language learning implementation has increased [5]. Some research has theoretically proven the effectiveness and some support the success by upgrading other aspects for substantiating its existence. However, those learning model innovations on localization issues are rarely touching the students' achievement. It still seldom even rare that the researchers discuss how the assessment is implemented in

Manuscript received March 19, 2019; revised June 14, 2019. This work was supported in part by Institute for Research and Development, Binus University.

Aryusmar is with Language Center, Computer Science Department, Faculty of Humanities Bina Nusantara University Jakarta, Indonesia (e-mail: aryusmar@binus.ac.id).

Wiwiek Afifah is with Graduate School of Language Educational Science, Yogyakarta State University, Indonesia (e-mail: wiwiekafifah.2018@student.uny.ac.id). language learning mainly for culture-based of English as a foreign language in higher education. Furthermore, when they did it, sometimes a mismatch between learning content and the process is frequently found [6].

However, they cannot be blamed because assessing culture-based on English as foreign language learning is not as easy as other aspects. It is not only assessing their cognitive competence but also their understanding of the culture they learned. Madya [7] stated that learning culture is emphasized in learning the affective domain. Therefore, comprehensive observation must be done to know students' culturally communicative behavior. Moreover, the challenges become worse when it is not easy to distinguish among the culture since they increasingly resemble one another [8]. Then Liddicoat [5] also convinced that when bringing culture in the teaching and learning process, set of shared assumptions about the nature of language, culture and learning to shape an overall understanding of what it means to learn language must be considered. Thus, it proves that doing assessment of teaching English based culture needs a serious fundamental concept of understanding.

Realizing the assessment function in learning especially for cultural-based in foreign languages, it means that the heavy burden of the teachers or lecturer is more severe. It is because they must be fully responsible for conducting the intensive observations on student development during the learning process. Additionally, the demands in the $21 \mathrm{st}$ century are getting higher. It is a must for them to understand the command of the subjects they teach. The concepts and skills as the central aspects of the teaching must also be well mastered. Moreover, in disciplining students with care and diplomacy must be well respected. Therefore, Danielson [9] pointed out that incorporating issues such as global awareness and cultural diversity must be carefully brought to the classroom. Teachers or lecturers must know the concepts and skills which are prerequisite to the understanding of others. Teachers must also be familiar with the particular pedagogical approaches best suited to each discipline.

Having discussed the reality of assessment in culture-based English as a foreign language teaching and learning in the

21 st-century classroom, it is viewed that there is a need in this field. Either learners or lecturer must demand this guideline to be implemented in their teaching or learning practice. Therefore, this paper aims to present a holistic assessment for culture-based English as foreign language learning for higher education mainly for a non-English department in 21 st-century classroom. 


\section{LITERATURE REVIEW}

\section{A. Assessment in Language Learning}

Tosuncuoglu [1] stated that assessment is a foundation of teaching that has a critical role. In addition, Byram \& Phipps [10] defined that assessment as the process of gathering information about student learning. This can encompass standardized language tests. Assessment is external to an ongoing process of learning and teaching, including much of the formal educational assessment [11]. Although, there are several different definitions dealing with assessment emerging, these evaluate the learning process as well as the learners' competence.

Furthermore, Brown [12] explains that assessment is "an ongoing process". It encompasses a much wider domain. Assessment is done subconsciously by teachers such as asking learners to give a response to certain questions, observing learners' performance from the written work-from some formal essay or learners' spoken performance. Brown emphasized that a good teacher never ceases to assess learners, whether those assessments are incidental or intended. For Brown, assessment is under the teaching process and it encompasses testing.

In line with the argument proposed by some experts, in this current study, assessment is defined as the on-going process to investigate the learners' competence of the lesson they have learned by considering various aspects which relate to the learning process.

\section{B. Culture in English as a Foreign Language Learning}

There are several definitions and interpretations of the term culture. One of the most common definitions of culture is a higher existence of refined sensibility and the products are performed in art, music, literature, and activities which are shaped by the rules, ideas and habits embedded in society Baldock [13]. Whereas, culture in term of language teaching and learning based on Byram \& Phipps [11] refers to the pragmatic field. Culture is associated with a language being learned. However, Fantini [14] argues that cultural context is not adequately taught in language.

In addition, Byram \& Esarte-Sarries [15] state that language and culture teaching and learning is always inevitably around the world. Take for example in the British tradition which has largely been taken for granted and considered unproblematic.

Practically there are some approaches that need to be combined in language learning. The use of the learners' mother tongue for comparative analysis of own culture and foreign culture can be combined with the teaching of the foreign language as a subject and as the medium of the affective as well as the cognitive experience of foreign cultural phenomena. By considering this idea, there are some benefits that can be acquired. Firstly, language learning in the current sense of skill- acquisition can be enriched by the study of the nature of language as a social and cultural phenomenon (Language Awareness). Secondly, the study of language would, in turn, be combined with culture study emphasizing the procedures and processes of ethnography and using the combinations of 'texts' mentioned above. This would be carried out in the learner's native language. Thirdly, the direct experience of aspects of the foreign culture from the viewpoint of the foreign peer group would be in the foreign language, and this would, in turn, contribute to the language learning process [15].

Furthermore, to design an assessment of culture-based language learning, the concept of teaching language by integrating the culture proposed by Byram \& Esarte-Sarries [15] must be well considered. It is because they try to strengthen the existence of both the learners' local culture and the target culture. Some dimensions that are important in the context of teaching and learning language based on culture are Baldock [13] the semantic fields of the two languages, as well as the relationship to cultural meanings, Bisai \& Singh [3] language awareness, also has beneficial effects on the acquisition of linguistic skills by allowing learners to reflect on their learning and in turn will be supported by the experience of learning. Finally, the relationship between language learning and cultural experience is mutually supportive in that language learning may well be largely system-oriented emphasizing the acquisition of skilled use of structures and vocabulary whereas using the language as a medium and for experiencing and talking about cultural phenomena shifts the emphasis to fuller integration of system-knowledge and culture- knowledge.

\section{The 21st-Century Classroom of Higher Education}

There is a great dynamic in teaching English for the learners in higher education especially in this digital world Therefore, the lecturer must adjust to this situation. Optimizing web-based assessment can help the lecturer. Consider the findings of Price, Pierson \& Light [16] which shows that using web-based assessment reduces the need for teachers to frequently evaluate student knowledge through recall test and manually

Furthermore, technology has greatly driven the social lives of students [17]. Therefore, the use of technology as an effective way to promote higher education learners' engagement must be taken seriously. When the needs and interests of students are taken into account, this results in a passion for life-long learning. The lecturer, in this case, must have a responsibility to provide a new level of instruction that is relevant, effective, and socially engaging for students.

\section{RESEARCH METHOD}

This research uses a descriptive-qualitative research design with the interpretive-exploratory paradigm. It conducted at Bina Nusantara University, Jakarta, Indonesia from March to December 2018. The population is all non-English faculty lecturers and students and the samples selected by using simple random sampling with a lottery. The objective of the research will discuss how the re-conceptual framework of holistic assessment in English as a foreign language learning which focuses on culture. In addition, it also attempts to explain how holistic assessment is implemented in the 21st-century classroom. This re-conceptual effort is expected to give other alternatives on assessing learners' competence in learning English as a foreign language which focuses on culture. Therefore, the 
research questions formulated as follows: a). what are the needs, theoretical basis, the perception of lecturers and students on the holistic assessment of culture-based English as foreign language learning for higher education in the 21 st-century classroom? b). what is the re-conceptual framework of holistic assessment of culture-based English as foreign language learning for higher education in the 21 st-century classroom?

\section{DISCUSSION}

\section{A. The Needs Analysis}

Realizing the more complex problems in the classroom means requiring teachers or lecturers to make a more careful assessment. Concisely, there is a high need in bringing another assessment to the classroom. In this case, the intended assessment must be different from the others. It must be able to tract and to record what students have learned holistically. A holistic assessment means an assessment that considers the existence of students without reducing their potential in the classroom. The process of learning culture and English must be carefully weighed. Learning either local and target culture must be seen in balance and objective.

Seeing the complexity of assessment in culture-based, it is emphasized that assessment is not only about the qualitative and quantitative matter, but it is rather on how far teacher or lecturer can improve their educational outcomes through culture-based language learning assessment. How far, assessment can track the learners' will in learning English which is incorporated with culture.

As a consequent, the lecturer will never be the single actor in assessing the learners' targeted competence. In the holistic assessment, learners' existence is considered. This thought assumes that learners cannot be measured based on their single parameter. Therefore, this assessment is built from some approaches to assessment. They are self- assessment, peer assessment, classroom assessment, and authentic assessment, formative and summative assessment. The two last assessments are meant by objective assessment. Therefore, the holistic assessment is interpreted as a medium for monitoring the competence of learners in understanding cultural values through learning English

On the other hand, the benefits of an appropriate assessment system in learning English which is based on culture is not only to know learners' competence in mastering the lesson or the course but also to increase student learning motivation, engagement as well as a positive attitude towards the courses they have learned. Generally, after learners have passed in studying certain subjects, usually they already feel enough and don't want to study anymore. But a good assessment can stimulate learners to have a sense of curiosity and want to explore their lessons after learning.

Given that assessment is part of the assessment process of a culture-based English learning program, therefore it plays a very important role. In learning culture-based English language learning, the assessment process can certainly be done in various ways. Even at the beginning of the teaching and learning process. This is because what will be seen is the three domains in education: cognitive, affective, psychomotor from the learners holistically.

This idea is in line to the assessment which is proposed by Danielson [9] in which there are three types of assessment processes, namely tests, products and performance. Each of the types of assessments has its own characteristics and has its own model of assessment. While in holistic assessment for learning English as a culture-based foreign language, longitudinal observation should be attached because it will cover several aspects in enriching the process of gathering the information. It should be emphasized that to know and to investigate how far learners can internalize and actualize the values of the culture they have learnt.

\section{B. The Theoretical Analysis}

In this current study, a holistic assessment is determined as a judgment which will provide the information about: 1) the whole learners' English competence and performance and 2) learners' internalization and actualization of cultural values. The holistic assessment refers to a chance to include learners' real-life experiences in the 21 stcentury classroom context during the learning process. Since the main point in the assessment is measuring learners' whole competence (culture and English) thus tracking learners in the whole of the learning process must be done carefully. The expected assessment is intentionally done during the learning process started from the very beginning of the course until the end of the course.

Furthermore, the holistic assessment for teaching English as a foreign language which is based on culture can be brought to the 21 st-century classroom along with two different ways: a) examining learners using ongoing formative test, and b) by means of self-report or self-assessment, peer assessment, classroom assessment that are an internal or self- directed activity.

The technique of implementation can be varied. It can use e-assessment, online assessment; computer-assisted or mediated assessment and computer-based assessment or paper-based assessment. By using online progress cards, record writing keeping devices in Google classroom, web-based questionnaires using Google form of self-evaluation and peer assessment, offline rating scales, and checklists, or computer- assisted assessment will make the assessment process will be more effective. Whereas the content that will be assessed in the holistic assessment for culture-based English as a foreign language learning are those that relate to knowledge about Indonesia culture and English culture (as a target culture).

Holistic assessment for culture-based English language learning is derived from some approaches of assessments. This assessment also adopts the model of foreign language education proposed by [15]. It is mainly for four aspects: language awareness, cultural awareness, cultural experience, and language learning.

The concept of holistic assessment accommodates either the modern and traditional standardized assessment. The philosophical assumptions are in conducting assessment of all aspect must be considered. Standardized tests which are usually based on multiple-choice items, fill-in items, and short, restricted-response tasks as part of objective testing must also be used to balance the subjective and objective 
consideration in assessment. Those testing can be done in a blended model such as using web-based assessment, offline application, or even using paper-based assessment. The technique of the assessment can be varied.

\section{Discussion of Interview Analysis}

The results of the interview data conducted to 3 randomly selected fellow lecturers concerning the possibility of implementing the Holistic Assessment in the 21st-Century Classroom. Data show that all of them (100\%) support the implementation of the Holistic Assessment mainly for a non-English department in the 21st Century Classroom. In addition, they argue that the benefits of Holistic Assessment in the 21st Century English Learning Classroom can make the classroom be more interactive and communicative, the teaching materials are more varied, and increase the students' cultural awareness. It concluded that the English Lecturers of Non-English departments have positive perceptions of the application of the Holistic Assessment in the 21st Century Classroom.

\section{Discussion of Questionnaire Analysis}

Questionnaires distributed to 10 classes of non-English faculty, and from the total questionnaires collected, 10 questionnaires randomly selected from each class for analysis. The results of the sample analysis are as shown in Fig. 1 below, it is about The benefits of Holistic Assessment for Culture-Based, $78 \%$ of students agree and $20 \%$ strongly agree that the benefits of Holistic Assessment for Culture-Based Language Learning is not only to know learners' competence but also to increase student learning motivation, engagement as well as a positive attitude towards the courses.

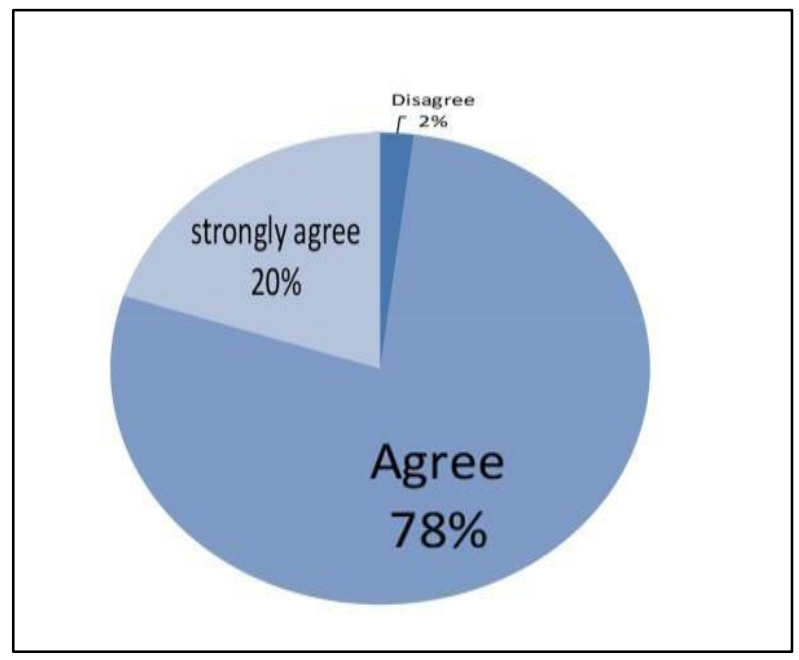

Fig. 1. Students' perception on the benefit of holistic assessment for culture-based language learning.

\section{RESEARCH FINDING}

\section{A. The Re-conceptualizing of Theoretical Framework}

Based on the result of examining the need analysis of a holistic assessment, the theoretical analysis of the holistic assessment approaches the lecturer's and students' perception toward the holistic assessment in the 21st-century classroom. The visualization of the Re-Conceptualizing of
Theoretical Framework of Holistic Assessment for Culture-Based Language Learning can be described in Fig. 2 as follows;

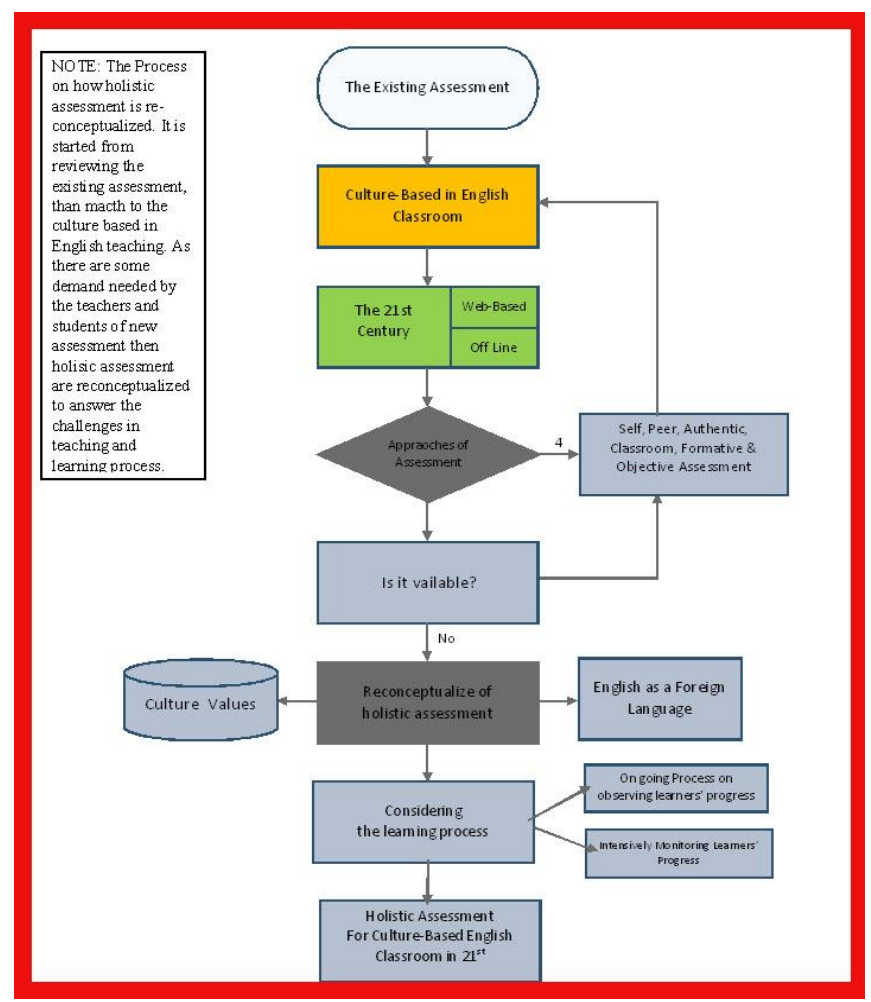

Fig. 2. The re-conceptualizing of theoretical framework of holistic assessment for culture-based language learning.

\section{B. The Re-conceptual of Implementing the Holistic Assessment in the $21^{\text {st }}$-Century Classroom}

The holistic assessment for culture-based English language learning for higher education learners refers to some fundamental concepts that the assessment is not a static element in language teaching and learning. As Freeman, Orzulack \& Morrissey [18] stated that is always changing. Therefore, there are some steps that can be conducted in implementing the holistic assessment for culture based learning as follows: $\bullet$ Explaining and informing learners the learning goals than monitoring their progress; -Formulating the level of achievement of cultural uunderstandings and competence in English learning; • Giving the example of good practice and quality work that reflect curriculum outcomes of the culture-based; • Learners work with other learners to develop clear criteria of good practice of cultural understanding in the language learning context; $\bullet$ Guide learners in developing internal feedback or self-monitoring; • Provide mechanisms to validate and question their own thinking, and to become comfortable with the ambiguity and uncertainty that is inevitable in learning anything new; $\bullet$ Lecturer provides regular and challenging opportunities to practice so that learners can become confident, competent as self- assessors; $\bullet$ Lecturer monitors learners' metacognitive processes as well as their learning and provides descriptive feedback; - Lecturer creates an environment where it is safe for learners to take chances and where support is readily available such as learners are free to give others comment toward their friends' competences. 


\section{CONCLUSION}

The research concluded that the re-conceptualizing holistic assessment of culture-based English as foreign language learning for higher education in the 21 st-century classroom, in this case, refers to some fundamental concepts of theoretical framework of holistic assessment for culture-based language learning which based on the integration of the modern assessment such as self-assessment peer-assessment, authentic assessment, classroom assessment, and the objective assessment either formative and summative assessment. In addition, the 21st-century classroom is more dynamic thus the assessment that will be used by English lecturer must be well comprehensive. Therefore, the new classroom condition of the 21 st century should be used as the basic consideration of learners' needs. Finally, the implementation of holistic assessment for higher education in the 21 st-century classroom can be done using online assessment or web-based assessment in which lecturer can directly upgrade the existing assessment to be a blended model of assessment.

\section{IMPLICATION}

The implication of this research is that the re-conceptualizing holistic assessment framework of culture-based English as a foreign language learning for higher education in the 21st-century classroom of non-English faculty at Universities in Indonesia should significantly be innovated; consequently, universities, especially Bina Nusantara University should upgrade the existing assessment.

\section{CONFLICT OF INTEREST}

We as the authors have no conflict of interest in the submitted work.

\section{AUTHOR CONTRIBUTION}

We have done it together with pleasure in accordance with the respective roles that we have agreed on, namely: Aryusmar as a chairman (The $1^{\text {st }}$ author) and Wiwiek as a member (The $2^{\text {nd }}$ author).

Aryusmar proposed a draft of several research topics and together with Wiwiek decided on the research topic to be chosen. Wiwiek helped to find and analyzed theoretical references. Aryusmar determined the research methodology and did the research at Binus University as well as analyzed data as the results of interviews and questionnaires. Then, we together determined the research findings, and conclusions. Finally, all authors had approved the final version.

\section{REFERENCES}

[1] I. Tosuncuoglu, "Importance of assessment in ELT," J. Educ. Train. Stud., vol. 6, no. 9, pp. 163-167, 2018.

[2] A. Green, "Assessment for learning in language education," Iranian Journal of Language Teaching Research, pp. 9-18, 2018.
[3] S. Bisai and S. Singh, "Rethinking assessment - A multilingual perspective," India's High. Educ. Auth. UGC, vol. 18, no. 4, April, pp. 308-319, 2018.

[4] N. Cowie and K. Sakui, "Assessment and e-learning: Current issues and future trends," jaltcall J., vol. 11, no. 3, pp. 271-281, 2015.

[5] A. J. Liddicoat, "Language teaching and learning from an intercultural perspective," Handbook of Research in Second Language Teaching and Learning Volume II, New York: Routledge, pp. 837-855, 2011.

[6] A. E. Fantini, "An essential component of intercultural communicative competence," The Routledge Handbook of Language and Intercultural Communication, New York: Routledge, pp. 263-278, 2014.

[7] S. Madya, Metodologi Pengajaran Bahasa: Dari Era Prametode sampai Era Pascametode, Yogyakarta: UNY Press, 2013.

[8] C. Kramsch and M. Uryu, "Intercultural contact, hybridity, and third space," The Routledge Handbook of Language and Intercultural Communication, New York: Routledge, California: ABC- CLIO, Inc, pp. 211-225, 2014.

[9] C. Danielson, "The framework for teaching evaluation instrument: 2013 EDITION,” Danielson Group, 2013.

[10] M. Byram and A. Phipps, Context and Culture in Language Teaching and Learning, Clevedon: Multilingual Matters LTD, 2002.

[11] J. W. Pellegrino, The Evolution of Educational Assessment: Considering the Past and Imagining the Future, Princeton: Policy Evaluation and Research Center, 2004.

[12] H. D. Brown, Language Assessment. Principles and Classroom Practices, Harlow: Longman, 2004.

[13] P. Baldock, Understanding Cultural Diversity in the Early Years, California: Sage Publication Ltd, 2011.

[14] A. E. Fantini, "Multiple strategies for assessing intercultural communicative," The Routledge Handbook of Language and Intercultural Communication, New York: Routledge, pp. 390-405, 2014.

[15] M. Byram and V. Esarte-Sarries, Investigating Cultural Studies in Foreign Language Teaching: A Book for Teachers Multilingual Matters (Series), vol. 62, Clevedon Philadelphia: Multilingual Matters, 1991.

[16] J. K. Price, E. Pierson, and D. Light, "Using classroom assessment to promote 21 st century learning in emerging market countries," Global Learn Asia Pacific, pp. 1-11, 2011.

[17] M. K. Williams, "John Dewey in the 21 st century," J. Inq. Action Educ., vol. 9, no. 1, pp. 91-102, 2017.

[18] D. Freeman, M. M. Orzulak, and G. Morrisey, "Assessment in second language teacher education," The Cambridge Guide to Second Language Teachers Education, Cambridge: Cambridge University Press, pp. 77-90, 2009.

Copyright (C) 2019 by the authors. This is an open access article distributed under the Creative Commons Attribution License which permits unrestricted use, distribution, and reproduction in any medium, provided the original work is properly cited (CC BY 4.0).

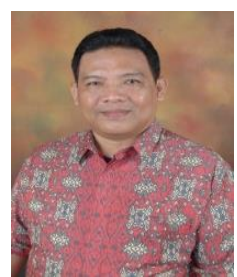

Aryusmar is associate professor as Faculty Member for Language Center, Computer Science Department, Faculty of Humanities Bina Nusantara University Jakarta Indonesia. He obtained the non-degree of TESOL from Hawthorn Institute of Education afiliated with Melbourne University 1996. He also got the non-degree of EAP from Saint Michael's College Overseas Studies 1997. He completed his doctoral degree in language education from Jakarta State University Indonesia 2004. He has published several articles and presented his papers in international conferences.

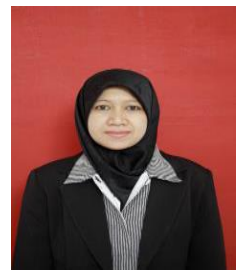

Wiwiek Afifah was born in Tuban, East Java Indonesia. She graduated from Ahmad Dahlan University for English Department and Education Study Program. She got her master of applied linguistics on English language education at Yogyakarta State University. She studies in Graduate School of Language Educational Science at Yogyakarta State University. 